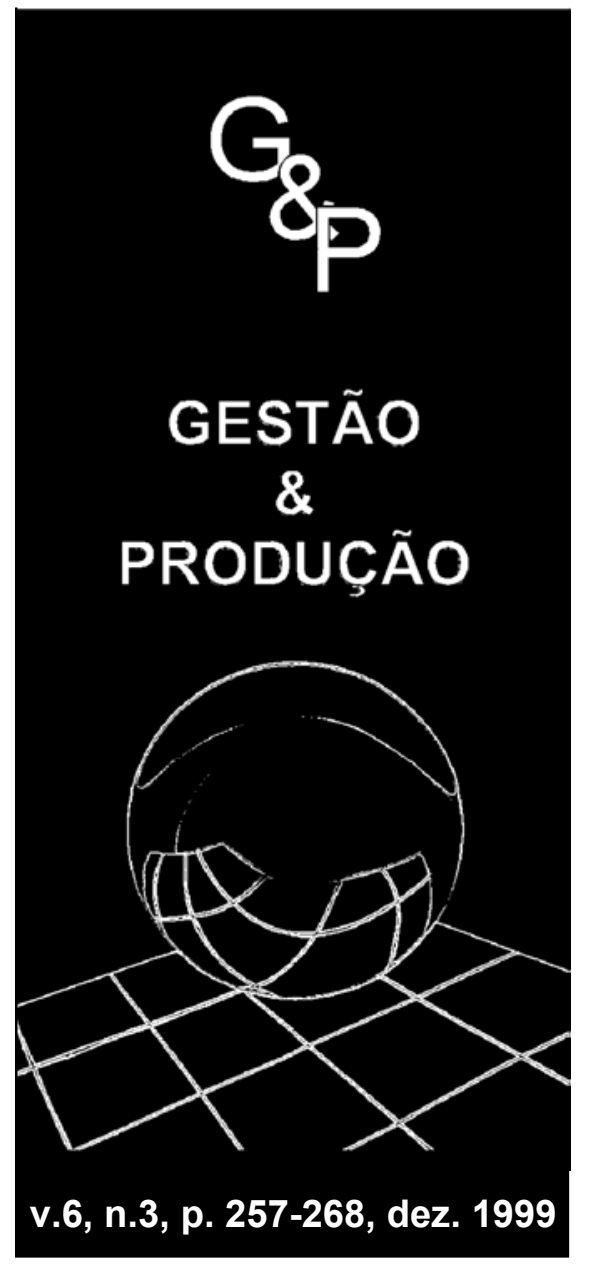

\title{
DECISÕES FINANCEIRAS EM COOPERATIVAS: FONTES DE INEFICIÊNCIA E POSSÍVEIS SOLUÇÕES
}

\author{
Sérgio Giovanetti Lazzarini \\ Washington University \\ Pesquisador do PENSA - Programa de Estudos dos \\ Negócios do Sistema Agroindustrial \\ E-mail lazzarinis@mail.olin.wustl.edu \\ Sigismundo Bialoskorski Neto \\ FEA/USP - Campus de Ribeirão Preto \\ Pesquisador do PENSA \\ E-mail sbialosk@usp.br \\ Fabio R. Chaddad \\ University of Missouri-Columbia \\ Pesquisador do PENSA \\ E-mail frcbb6@mizzou.edu
}

\section{Resumo}

Este trabalho explora o impacto de determinadas características organizacionais de cooperativas sobre suas decisões financeiras. Procede-se a uma análise teórica da questão financeira em tais organizações, definido-se variáveis importantes para o estudo da estrutura de capital e das decisões de investimento, tais como a natureza do patrimônio, o custo do capital, os incentivos organizacionais e a especificidade de ativos. $O$ desafio principal refere-se ao desenho e implementação de uma estrutura organizacional visando aumentar a disponibilidade de capital próprio, permitindo a contração de um nivel eficiente de capital de terceiros. Outro desafio refere-se à geração de incentivos organizacionais para a seleção de projetos que adicionem valor à empresa, evitando-se um nível excessivo de investimentos - um problema típico em cooperativas devido à tendência de se subestimar o custo do capital próprio. Este estudo é de ordem conceitual e sugere alguns tópicos relevantes para futuras pesquisas de ordem teórica e empírica.

Palavras-chave: cooperativas, direitos de propriedade, finanças, estrutura de capital, decisões de investimento.

\section{Introdução}

FAMA \& JENSEN (1985) argumentam que diferentes formas organizacionais, definindo estruturas distintas de direitos de propriedade sobre os "resíduos" e controle da empresa, irão afetar diretamente o processo de tomada de decisão no âmbito financeiro. Assim é no caso 
de cooperativas, que têm passado por profundas transformações nos últimos tempos, destacandose mudanças na gestão financeira em decorrência das limitações impostas pelas suas próprias características de arquitetura organizacional.

Os princípios doutrinários do cooperativismo estabelecem feições particulares a tais organizações, pelo fato dos direitos de controle não serem proporcionais ao capital (em função do princípio de "um homem, um voto"), e pela característica de organização com objetivos mais amplos que a simples maximização do lucro. $\mathrm{O}$ objetivo principal da cooperativa é aumentar o bem-estar do seu quadro de membros. Em outras palavras, o escopo da função objetivo da cooperativa depende sobremaneira dos objetivos individuais de cada membro ou sócio (COOK, 1994a). Logo, quanto mais heterogêneo for o quadro de membros, mais amplo será o objetivo da organização. Muitas vezes, as cooperativas são confundidas com organizações sem fins lucrativos, esquecendo-se do fato de que os resultados são uma condição necessária, mas não suficiente, para se aumentar o bem-estar dos associados. Tal problema é exacerbado pelo fato do resultado líqüido do exercício em cooperativas ser denominado de "sobras operacionais", ao invés de lucro.

No Brasil, as cooperativas apresentam a característica de não profissionalização da gestão. Ou seja, na maioria dos casos os próprios cooperados assumem funções diretivas na empresa, não havendo a completa separação entre a propriedade e o controle (ZYLBERSZTAJN, 1993). No caso de empresas de capital aberto, a separação entre propriedade e controle leva ao clássico problema do agente-principal (JENSEN \& MECKLING, 1976). Em outras palavras, a função administrativa relacionada à implementação de projetos e a função de controle efetuada pela ratificação de decisões e seu monitoramento são normalmente desempenhadas pelos mesmos agentes (BIALOSKORSKI NETO, 1997). Vale citar que isto não ocorre na maior parte das cooperativas em países desenvolvidos, onde administradores profissio- nais são recrutados do mercado para gerir as empresas cooperativas.

Estas características que regem a coordenação do processo de decisão, transferência de informações, incentivos e controle interno da organização - processo esse denominado governança - acabam influenciando de modo particular a gestão financeira de cooperativas.

Em empresas estruturadas como sociedades de capital aberto observa-se que o objetivo de maximização do valor da empresa, por meio da seleção de projetos com base no seu valor presente líqüido, é compatível com o objetivo primordial da gestão financeira, que é aumentar a riqueza do acionista (assumindo-se, é lógico, que os gerentes podem ser monitorados a baixo custo pelos acionistas da empresa). Por outro lado, sendo o acionista o detentor dos direitos sobre o "resíduo" da empresa, o qual não precisa assumir qualquer outro papel na organização, possibilita-se o desenvolvimento de um mercado secundário para estes direitos, que se especializa na sua precificação e transferência a outros proprietários sob baixos custos de transação (FAMA \& JENSEN, 1983).

Em cooperativas, tal objetivo não é tão claro, uma vez que o cooperado é, ao mesmo tempo, fornecedor e proprietário da organização e, muitas vezes, também cliente, quando da compra de insumos. A relação cooperado-cooperativa é portanto muito mais complexa, envolvendo o fornecimento de produtos e o recebimento de serviços, o pagamento destes produtos, e eventualmente a distribuição de sobras operacionais. Destarte, o cooperado passa a ser agente e principal da mesma relação contratual, participando do processo de decisão e se "autocontratando" para fases posteriores deste processo (BIALOSKORSKI NETO et al., 1995).

Além disso, o capital que o cooperado fornece à cooperativa - a sua quota-parte - é um título que não é remunerado e nem apresenta um mercado secundário com liqüidez suficiente para permitir a troca rápida e a baixo custo de direitos de propriedade (ZYLBERSZTAJN, 1994). A administração deste duplo papel de 
usuário/fornecedor e proprietário da mesma organização desempenhado pelos associados é um desafio de difícil solução comum a cooperativas em todo o mundo.

A estrutura organizacional cooperativa, caracterizada por direitos de propriedade sobre o "resíduo" pouco definidos e não transacionáveis, impõe ineficiências trazidas pelas mais diversas distorções. Cabe lembrar que tais ineficiências organizacionais da estrutura cooperativa são de caráter teórico e ainda não foram definitivamente corroboradas por estudos empíricos. Para uma revisão da literatura acerca do desempenho econômico de cooperativas com relação a outras formas organizacionais veja SEXTON \& ISKOW (1993). As distorções mais comumente citadas são as seguintes (VITALIANO, 1983; COOK, 1995):

- A ação de "caronas" (free-riders) que podem se aproveitar de externalidades positivas geradas pela cooperativa ("caronas externos") e de investimentos feitos por gerações anteriores ("caronas internos");

- Uma vez que o direito ao resíduo não é transacionável e, portanto, o seu valor não contabiliza os fluxos de caixa esperados no futuro, existem desincentivos à capitalização da cooperativa quando a vida útil dos ativos for superior ao horizonte temporal dos benefícios recebidos pelos associados;

- A inexistência de mercado secundário para as quotas também gera restrições sobre a carteira de investimentos dos cooperados (normalmente avessos ao risco), fato que pode induzi-los a influenciar as decisões de investimento da cooperativa, eventualmente não aceitando projetos com valor presente líqüido reduzido e/ou fluxos de caixa altamente variáveis. Deve-se ressaltar que há casos em que o cooperado acaba por aceitar projetos de fluxos de caixa de maior variabilidade pela provável questão da existência de assimetria de informações própria da arquitetura organizacional das cooperativas (BIALOSKORSKI NETO, 1998);

- Problemas de controle, pela necessidade de monitoramento da cooperativa de forma mais intensa e custosa para reduzir ações oportunistas dos seus administradores; e

- Custos de influência que geram ineficiência alocativa por resultarem de conflitos distributivos entre grupos específicos de cooperados favorecendo objetivos individuais acima dos coletivos.

O presente trabalho visa discutir como tais problemas de cunho organizacional acabam trazendo dificuldades às decisões de financiamento e investimento em cooperativas, e como as ineficiências resultantes podem ser dirimidas. Primeiramente, apresentam-se aspectos relacionados às decisões de financiamento, a partir de uma breve discussão sobre a escolha da estrutura de capital em cooperativas e alternativas à sua capitalização por meio de recursos próprios. O caso da cooperativa canadense Saskatchewan Wheat Pool serve de ilustração para a análise conceitual. Em seguida, apresentam-se aspectos ligados às decisões de financiamento, em particular com respeito a distorções trazidas pelo custo médio ponderado de capital. Realiza-se então uma discussão acerca do efeito da especificidade de ativos sobre as decisões financeiras de cooperativas. Considerações finais encerram o trabalho, gerando sugestões para futuras pesquisas empíricas.

\section{Decisões de Financiamento}

\subsection{Estrutura de Capital}

【m aspecto crucial relacionado às decisões de financiamento de empresas é a definição de uma estrutura de capital ótima, com respeito à proporção entre dívidas (capital de terceiros) e patrimônio (capital próprio) como fontes alternativas de recursos. MODIGLIANI \& MILLER (1958), em trabalho clássico sobre o tema, argumentaram que não existe uma estrutura de capital ótima se o mercado de capitais for perfeito, porque neste caso os investidores conseguem ajustar a configuração de risco e retorno de seus portifólios de acordo com a alavancagem da empresa. Em um mercado de capitais perfeito, 
investidores têm acesso ao mercado de capitais sob as mesmas condições (isto é, mesmo custo de capital) que as empresas. Desta forma, para um investidor individual tanto faz se a empresa é alavancada ou não, pois ele tem a possibilidade de ajustar seu portifólio de acordo com sua preferência com relação ao risco. Sob estas condições, o valor de mercado da empresa é independente de sua estrutura de capital, e somente varia de acordo com o valor presente líqüido dos seus projetos de investimento.

A literatura reconhece, entretanto, fatores que acabam permitindo definir vantagens para uma ou outra fonte de capital, tais como os efeitos de impostos, custos de falência, questões de sinalização ao mercado, problema de relação agente-principal, arquitetura da firma, setor econômico de atuação, dentre outros. $\mathrm{O}$ resultado desta discussão é que ainda não se chegou a um consenso sobre o tema (HARRIS \& RAVIV, 1991; MYERS, 1984).

WEDIG et al. (1996) discutem como a característica de organização sem fins lucrativos pode influenciar a decisão sobre estrutura de capital, ressaltando o incentivo para a obtenção de capital de terceiros em função das limitações de obter capital próprio, muito embora tais organizações não tenham as vantagens de obtenção de capital de terceiros relacionadas à redução de impostos, por serem isentas. O modelo teórico do autor e a sua aplicação empírica demonstram que organizações sem fins lucrativos apresentam características particulares no tocante às decisões de financiamento da firma.

No âmbito de cooperativas, a estrutura de capital é um aspecto cujo aprofundamento está ainda para ser feito por meio de modelos teóricos e estudos empíricos. Existe uma farta literatura sobre o tema nos Estados Unidos, mas suas implicações não podem ser generalizadas uma vez que as análises são específicas às características do ambiente institucional daquele país. $\mathrm{O}$ fato concreto é que tais organizações, por apresentarem fortes limitações ao aporte de capital próprio, acabam tendo que recorrer fortemente a dívidas para financiar seu crescimento. Este fato não seria propriamente um aspecto negativo se os custos financeiros das cooperativas não fossem tão elevados. Isto ocorre em função da sua baixa flexibilidade em captar recursos próprios, da existência de ativos específicos, que perdem valor quando direcionados a outros usos ou usuários (conforme será discutido na seção 4), e da morosidade em efetuar adaptações na linha estratégica dos seus projetos devido às limitações impostas por decisões em assembléia. Ademais, as cooperativas apresentam um risco adicional ao agente financeiro, no caso particular brasileiro, por não estarem sujeitas a legislação específica de falência.

O ponto central que determina a baixa capacidade das cooperativas em levantar recursos próprios está relacionado ao problema de direitos de propriedade sobre o "resíduo" não transacionáveis e não proporcionais ao capital investido pelo cooperado. Em outras palavras, a arquitetura organizacional da cooperativa não gera incentivos aos associados para a sua capitalização, uma vez que a quota-parte não apresenta mercado secundário desenvolvido e as "sobras operacionais" repartem-se de acordo com a movimentação do cooperado em termos de compra/venda de produtos, ou seja, do seu volume de transação com a cooperativa.

Neste contexto, observa-se os incentivos quase nulos para que o cooperado invista em mais quotas-partes e, portanto, capitalize a cooperativa (COOK, 1995; COOK \& ILIOPOULOS, 1998). Vale citar que somente o fato da inexistência de mercados de capitais eficientes para as quotas da cooperativa e a conseqüente má avaliação do capital próprio (aspecto a ser discutido na seção 3) já acabam drenando as hipóteses básicas do argumento de MODIGLIANI \& MILLER. Portanto, a decisão sobre a estrutura de capital de cooperativas torna-se relevante, isto é, a alavancagem da empresa cooperativa pode afetar seu valor de mercado.

Até mesmo no âmbito de capital de terceiros, ou de contração de dívidas, as cooperativas apresentam problemas. Especialmente no Brasil, o insucesso passado de muitas cooperativas 
acabou sinalizando ao sistema financeiro que se trata de um cliente de alto risco de crédito, podendo aumentar o custo do empréstimo e/ou o nível de garantias e, no limite, restringir o fornecimento de recursos. Este problema foi solucionado nos Estados Unidos com um sistema de bancos cooperativos, o Farm Credit System, que conta com um banco exclusivamente para fornecer crédito às cooperativas agrícolas (Bank for Cooperatives). Atualmente no Brasil estão em operação os dois primeiros Bancos ligados ao sistema cooperativo, BANCOOB e BANSICREDI, controlados pelas cooperativas de crédito. Além disso, as cooperativas brasileiras não têm - tal como sociedades anônimas ou limitadas - uma legislação consolidada para casos de falência, que possa permitir ao credor acionar procedimentos legais para obter de volta seus recursos.

Por fim, além de ter de financiar a si própria, a cooperativa acaba muitas vezes financiando o cooperado, para garantir a aquisição de uma determinada quantidade de produtos e/ou venda de insumos. No Brasil, a dependência dos cooperados pelo crédito repassado pelas cooperativas exacerbou-se a partir da década de 80 , com o desmantelamento do sistema federal de crédito rural. Isto traz complicações adicionais para o equacionamento do nível de liqüidez da cooperativa e da seleção de fontes de crédito adequadas e compatíveis com o nível de renda do cooperado.

\subsection{Alternativas para a Capitalização de Cooperativas}

Diversas alternativas têm sido propostas para contornar tais problemas. A saída mais comum é limitar o financiamento de projetos com recursos próprios. Entretanto, esta pode não ser uma estratégia ótima, porque poderá limitar o crescimento da cooperativa por meio de investimentos em projetos de maior escala ou, o que é ainda pior, induzir a cooperativa a investir em projetos de pequena escala, que podem não ser competitivos. Em um trabalho empírico, FULTON et al.
(1995) demonstraram que a taxa de crescimento das sete maiores cooperativas dos Estados Unidos e Canadá desde 1948 não é estatisticamente diferente de zero, apontando a dificuldade de obtenção de capital próprio permanente como a principal restrição ao crescimento entre as cooperativas estudadas.

Há que se citar, entretanto, que a opção pelo não crescimento pode representar menores custos de controle e menores perdas residuais trazidas pelo problema do agente-principal e custos de influência (HANSMANN, 1996). Uma baixa escala de operação tende a facilitar o processo de monitoramento por parte dos cooperados e propiciar um maior alinhamento de interesses, favorecendo a tomada de decisão coletiva. Por esta razão, é comum o argumento que o crescimento da cooperativa é uma das principais causas das distorções já discutidas anteriormente (COOK, 1995). Contudo, a pressão competitiva trazida por outras organizações pode significar séria ameaça à sobrevivência de cooperativas de pequeno porte em uma perspectiva de longo prazo.

Os maiores desafios, entretanto, surgem da necessidade de se encontrar alternativas de obtenção de recursos próprios, que possibilitem o crescimento da cooperativa. De forma geral, os principais mecanismos analisados têm sido os seguintes:

- Abertura de empresa não-cooperativa (sociedade anônima ou limitada). Neste caso, ao invés da cooperativa investir diretamente seus recursos em ativos produtivos, tal como uma planta industrial, passaria a investir em participação acionária em empresas nãocooperativas, com maior flexibilidade de aporte de recursos. Como efeito secundário, tal modelo acaba facilitando a concretização de alianças estratégicas com outras empresas. Esta estratégia foi adotada com sucesso pela Cebeco-Handelsraad na Holanda (ZYLBERSZTAJN, 1993) e Gold Kist nos Estados Unidos (SCHRADER, 1989).

- Emissão de títulos. A sociedade cooperativa emitiria, a exemplo das empresas de capital 
aberto, títulos para promover a sua capitalização. Torna-se preciso, entretanto, adequar a legislação existente para possibilitar a emissão de títulos por cooperativas no Brasil e também para gerar um ambiente institucional específico que dê suporte à atuação de investidores. Outro entrave é o acesso ao mercado de capitais, muitas vezes restrito a empresas de grande porte ou com alta qualidade de crédito (COOK \& ILIOPOULOS, 1998).

- Abertura de capital da cooperativa. Diversos modelos têm sido propostos, mas a idéia básica é criar uma estrutura híbrida na qual as quotas são transformadas em ações ordinárias (portanto, com direito a voto) e são lançadas ações preferenciais no mercado. Esta estratégia foi adotada pela Saskatchewan Wheat Pool no Canadá (BIALOSKORSKI NETO, 1998) e Kerry Cooperative na Irlanda (JACOBSON \& O'LEARY, 1990). Entretanto, tal modelo apresenta algumas restrições doutrinárias e legais, pela inexistência de legislação específica prevendo este tipo de operação em cooperativas.

- Contratos de participação. Neste caso, um determinado grupo de produtores com objetivos específicos se junta para financiar o investimento da cooperativa em um determinado projeto (por exemplo, um grupo de suinocultores decide investir em um abatedouro, cujo projeto será coordenado pela cooperativa). $\mathrm{O}$ processo envolve um contrato com a cooperativa no qual os produtores teriam participação no resultado da empresa de forma proporcional ao capital investido (COOK, 1994b; BIALOSKORSKI NETO,

- Co99p)erativas de nova geração (New Generation Cooperatives). Trata-se de um novo movimento cooperativista surgido no meio-oeste americano no início dos anos 90 , onde cooperativas locais são formadas com o objetivo de adicionar valor à produção dos associados, por meio de processamento e estratégia de marketing. Para tal, a cooperativa demanda investimentos de cada cooperado em proporção a sua entrega de produtos, emitindo "títulos de entrega" (delivery rights). Tais títulos são transacionáveis somente entre os membros da cooperativa, pois o título não é somente um direito ao resíduo, mas um contrato que obriga o cooperado a entregar a quantidade predeterminada do produto na qualidade especificada. Ou seja, criam-se incentivos para os membros investirem na cooperativa na proporção de seu uso, eliminando-se o problema de "caronas internos". Entretanto, esta obrigação de investimento por parte dos associados causa barreiras à entrada para produtores com recursos escassos. Outro redesenho organizacional adotado é o voto proporcional, ou seja, os direitos de voto são proporcionais aos "títulos de entrega" (HARRIS et al., 1996).

- Conversão para empresa de capital aberto. Trata-se da estratégia mais radical, isto é, abandonar a organização cooperativa e convertê-la em empresa de sociedade anônima. Muitas cooperativas de sucesso em países desenvolvidos decidiram-se pela conversão. COLLINS (1991), analisando tais casos, concluiu que as conversões são motivadas pela necessidade das empresas em questão de ter acesso a recursos próprios com custo de capital compatível com suas atividades econômicas.

Algumas alternativas parecem ser particularmente interessantes para algumas cooperativas, como os contratos de participação nas cooperativas altamente diversificadas, no qual um determinado investimento pode favorecer um certo grupo de cooperados mas deixar os restantes indiferentes ou até mesmo em pior estado. Isto pode ocorrer, por exemplo, quando recursos financeiros escassos induzirem a competição por diferentes projetos com efeitos distributivos assimétricos no quadro de cooperados, o que é uma situação bastante comum.

Mas antes de se pensar em qualquer solução alternativa de financiamento é preciso avaliar os custos comparativos de cada modalidade. O processo de abertura de capital demanda custos não desprezíveis relacionados à atração de novos 
investidores e também à perda de isenções fiscais. Do mesmo modo, a constituição de alianças estratégicas nem sempre é factível, devendo considerar quais tipos de resultados sinérgicos podem ser obtidos no processo, em particular o que a cooperativa tem a oferecer a eventuais parceiros.

Cooperativas agrícolas deveriam explorar especialmente as suas vantagens competitivas relacionadas ao contato direto com o produtor e uma possível maior capacidade de coordenação da cadeia de suprimentos, aspecto que pode ser interessante para empresas mais focadas em estágios de processamento e distribuição de produtos para consumidores finais. Em outras palavras, as decisões financeiras e organizacionais dependem da estratégia competitiva adotada.

\subsection{Abertura de Capital: o Caso Saskatchewan Wheat Pool}

A Wheat Pool é uma das maiores cooperativas canadenses, atuando no mercado de grãos. Conta com aproximadamente 60 mil membros ativos e um faturamento da ordem de US\$ 1,5 bilhão. Esta cooperativa abriu o seu capital por meio de ações ordinárias ("Share A"), oferecidas aos seus cooperados, e ações preferenciais ("Share B") colocadas aos cooperados e ao público em geral. Apesar da grande preocupação em manter a identidade de empresa cooperativa, o caso gerou polêmica no meio cooperativista canadense e internacional.

A abertura de capital por meio de ações preferenciais, sem direito a voto, encontra um obstáculo quase intransponível nas cooperativas fortemente enraizadas em princípios doutrinários. Do mesmo modo, se as ações ordinárias permitirem o direito de voto proporcional ao capital investido, ocorre uma mudança na alocação dos direitos de decisão da cooperativa, descaracterizando o princípio doutrinário de "um homem, um voto".

A estratégia da Wheat Pool no Canadá foi de gerar resultados financeiros suficientes para ganhar credibilidade no mercado e possibilitar a abertura de seu capital. Ao mesmo tempo, a cooperativa manteve a estrutura de decisão e controle intacta, com ações ordinárias sendo transacionadas apenas entre associados, mantendo-se a proporção de um voto para cada cooperado. Isto também permitiu que fossem pagos dividendos para as ações preferenciais, gerando incentivos para a entrada de investidores externos no processo.

A cooperativa decidiu pela abertura do capital em 1991, com o objetivo de aliviar o custo de sua estrutura de capital fortemente enraizada em capital de terceiros. Em 1995, o plano de reestruturação da estrutura de capital foi iniciado e, em 1996, foram colocados 305 milhões de dólares canadenses em ações para serem adquiridos inicialmente dentro da cooperativa. Em 1996, foram negociados mais 153 milhões de dólares canadenses em ações de classe B na Bolsa de Valores de Toronto. As ações apresentaram uma rápida valorização, tendo como garantias o pagamento mínimo de dividendos para os investidores, o que contribuiu para o seu sucesso. Em 1997, houve o primeiro pagamento de dividendos.

A abertura do capital propiciou o estabelecimento de um ambicioso plano de investimentos e crescimento da cooperativa. Além da abertura do capital, a cooperativa concretizou uma série de alianças estratégicas de negócios $e$ joint ventures formadas por meio de empresas nãocooperativas, que auxiliam na condução eficiente de negócios em várias áreas operacionais. $\mathrm{O}$ alinhamento da estrutura de capital com a estratégia competitiva é o ponto-chave para o sucesso do modelo organizacional adotado pela Wheat Pool.

\section{Decisões de Investimento}

U $\mathrm{m}$ aspecto fundamental para o balizamento de decisões de investimento é a determinação do custo marginal ponderado de capital (CMPC) da empresa, que irá permitir descontar o fluxo de caixa esperado de um dado projeto e avaliar o seu valor presente líqüido. Considere-se 
que $k_{t}$ e $k_{p}$ representem respectivamente o custo marginal do capital de terceiros (dívidas) e próprio (patrimônio) e que $t$ (sendo $0 \leq t \leq 1$ ) represente a participação de dívidas na estrutura de capital. Tomando-se a decisão sobre a estrutura de capital $(t)$ como exógena, o CMPC será:

$$
C M P C=t \cdot k_{t}+(1-t) \cdot k_{p}
$$

No caso de cooperativas, do mesmo modo que em empresas de capital aberto, o cálculo do custo do capital de terceiros é uma tarefa relativamente fácil, bastando informar-se das diversas linhas de crédito disponíveis. A dificuldade reside em se definir o custo do capital próprio da cooperativa. Como parte dos recursos próprios devem ser retidos em fundos indivisíveis, em função de exigências de cunho legal e estatutária, acaba havendo uma sensação de que o capital próprio não tem custo ou tem custo muito baixo (REQUEJO, 1997).

Imaginando-se uma situação em que o custo marginal do capital próprio seja nulo, então o CMPC se tornará igual a:

$$
C M P C=t . k_{t}
$$

Portanto, quando houver participação de capital próprio (ou seja, $t<1$ ), o CMPC será subestimado, isto é, viesado para baixo. Neste sentido, problemas diversos tais como a falta de monitoramento sobre os agentes da cooperativa e grupos de influência podem induzir a seleção de projetos com valor presente líqüido negativo. Por exemplo, um determinado grupo de cooperados pode articular pressões políticas para a implantação de um determinado projeto que os favoreça, ainda que ocorra perda de bem-estar para o sistema como um todo. Vale citar que a perda de bem-estar será condicionada não apenas pela aceitação de um projeto que pode ser ineficiente, mas também pelos custos de influência incorridos pelo grupo de interesse (MILGROM \& ROBERTS, 1992).

Assumindo-se uma determinação endógena da estrutura de capital, o baixo custo do capital próprio deverá induzir um aumento na participação desta fonte de recursos, reduzindo $t \mathrm{e}$ tornando o CMPC ainda mais baixo. Obviamente, recursos próprios são restritos, não permitindo ser a única fonte de financiamento em cooperativas de grande porte. Ainda que o capital próprio possa ser o mais atraente, deverá ser cada vez mais escasso com o crescimento da cooperativa, o que é agravado pelos problemas de governança decorrentes do aumento de escala, aumentando-se as ineficiências e, portanto, reduzindo as "sobras operacionais".

Existe, neste contexto, um incentivo para a aceitação de projetos que não agregam valor às cooperativas, devido à falta de percepção do custo do seu capital patrimonial. Mesmo no caso de organizações sem fins lucrativos, a seleção de projetos com valor presente líqüido positivo pode ser considerada como regra de decisão de investimentos pela simples necessidade de sobrevivência face à competição com outras organizações, visem elas o lucro ou não (FAMA \& JENSEN, 1985).

FAMA \& JENSEN (1985) discutem o caso de organizações sem fins lucrativos que competem por "doações", o que não é propriamente o caso de cooperativas. Quando do desenho de novos projetos, cooperativas poderão reduzir os entraves associados ao uso de capital de terceiros (custos elevados de dificuldades financeiras) se apresentarem razoável montante de capital próprio, o que é conseguido por meio da seleção dos projetos que gerem o máximo de "sobras", muito embora os mesmos possam eventualmente apresentar valor presente líqüido negativo para organizações de capital aberto pelo fato do CMPC tender a ser subestimado em cooperativas. Por outro lado, do ponto de vista do cooperado, sua riqueza será maximizada quanto maior a disponibilidade de "sobras" (se elas forem distribuídas), desde que isto não implique um menor retorno do negócio do cooperado, por exemplo se a cooperativa estabelecer menores preços a serem pagos pelos produtos do mesmo.

Para contornar este problema torna-se necessário, em primeiro lugar, estabelecer critérios internos de determinação do custo do capital 
próprio. Ou, o que seria melhor, deixar que o mercado de capitais o faça, por meio do estímulo ao desenvolvimento de mercado secundário para quotas e definição de uma política adequada de distribuição de "sobras". A negociação de títulos de cooperativas em mercado secundário permitiria, adicionalmente, uma mensuração adequada do seu real valor (assumindo um mercado de capitais informacionalmente eficiente), gerando incentivos mais fortes à busca de eficiência nas decisões de investimento e financiamento.

$\mathrm{O}$ fato de cooperativas serem algumas vezes encaradas como organizações sem fins lucrativos não é, per se, uma restrição para a constituição de um mercado secundário das quotas pois existem organizações que não visam lucros, como é o caso das bolsas de valores e futuros, nas quais o título societário (normalmente adquirido por corretoras) é negociado em mercado secundário e é valorizado de acordo com as perspectivas de movimentação nos pregões.

Outra medida que deveria ser buscada é evitar a alocação de recursos para fundos indivisíveis, que tendem a tornar nulo o custo do capital próprio e estimular a aceitação de maus projetos. Ademais, o crescimento em excesso dos fundos indivisíveis gera incentivos aos associados para liqüidar a cooperativa, pois trata-se da única forma de reaverem seus investimentos (SCHADER, 1989). Estas ações podem contrariar princípios doutrinários do cooperativismo, porém devem ser consideradas sempre que houver a perspectiva de ganhos de eficiência econômica para o sistema.

\section{Especificidade de Ativos}

U $\mathrm{m}$ determinado ativo é específico quando ocorre perda de seu valor econômico quando direcionado a usos ou usuários alternativos (WILLIAMSON, 1985). Cooperativas tendem particularmente a apresentar um nível elevado de especificidade locacional dos ativos, porque seus investimentos normalmente são direcionados a um determinado grupo de cooperados definidos regionalmente. Portanto, as quase-rendas geradas por tais ativos podem ser perdidas quando da saída da cooperativa da atividade econômica à qual os ativos foram direcionados.

Quando se deparar com investimentos específicos, a cooperativa deve analisar cuidadosamente os riscos aos quais se expõe se porventura surgirem distúrbios que possam pôr em risco a viabilidade do projeto. A falta de incentivos por parte dos cooperados em almejarem o máximo valor dos projetos de investimento da cooperativa pode induzi-los à troca de atividade sempre que tal ação resultar em ganhos para os mesmos. Conforme discutido por ZYLBERSZTAJN (1996), trata-se de um típico problema de quebra contratual gerado por ação oportunista, assumindo-se a atividade cooperativista como uma relação contratual "a jusante" da atividade produtiva.

Por exemplo, a cooperativa pode receber pressões políticas para a constituição de uma planta de processamento de um produto não pertencente ao seu core business para garantir o escoamento da produção de um determinado grupo de cooperados. Porém, se os produtores perceberem após a execução do projeto de investimento que a nova atividade é antieconômica e seus custos de saída são baixos, não hesitarão em cessar o processo produtivo. Neste caso, a planta industrial certamente perderá valor por se localizar em uma região com baixa oferta de matéria-prima.

Tais considerações têm particular relevância para a análise da diversificação de cooperativas. Estudos como os de TRECHTER (1996) e KATZ (1997) não encontraram propriamente uma relação inversa significativa entre $o$ desempenho da cooperativa e o nível de diversificação, porém nenhuma consideração é feita com respeito ao nível de especificidade dos ativos envolvidos. A diversificação será tão mais crítica quanto maior a participação de ativos específicos, uma vez que a cooperativa pode deparar-se com problemas de quebra contratual no suprimento de matérias-primas ou serviços.

Se os investimentos específicos realizados pela cooperativa forem acompanhados por investimentos específicos também por parte do cooperado, surgem quase-rendas em ambas as 
partes contratuais. Ou seja, surge uma situação de dependência bilateral, a qual desestimula a quebra contratual ineficiente entre o cooperado e a cooperativa. Não havendo esta relação de dependência, que pode ser interpretada como uma incongruência estratégica entre as partes, a probabilidade de rompimento do contrato, e conseqüentemente a perda de valor do investimento da cooperativa, tornar-se-á elevada (ZYLBERSZTAJN, 1996). Uma situação de dependência bilateral pode ser criada por investimentos do cooperado em títulos da cooperativa embutindo direitos sobre resíduo bem definidos, de acordo com mecanismos discutidos no item 2 .

A especificidade dos ativos também tem influência sobre as decisões acerca da estrutura de capital. Conforme discutido por WILLIAMSON (1988), investimentos específicos demandam a participação de fontes de recursos que garantam maior controle e maior poder de adaptabilidade a distúrbios externos diversos (por exemplo, uma situação de mercado adversa não esperada pelas partes contratantes). É o caso dos recursos próprios, uma vez que dívidas são muito pouco adaptáveis e tolerantes a tais distúrbios, porque os credores irão demandar um retorno certo (na forma de pagamento de juros sobre o principal), de acordo com as cláusulas contratuais preestabelecidas.

Desta forma, especialmente em situação de investimentos específicos (tais como a planta industrial anteriormente citada), torna-se preciso aumentar a participação de recursos próprios, especialmente a partir dos cooperados, para reduzir o risco de que distúrbios externos gerem o rompimento do contrato cooperado-cooperativa. Vale citar que tais recursos próprios devem necessariamente embutir incentivos para que seja observado o custo, conforme discutido na seção 4.

\section{Considerações Finais}

presente texto teve por objetivo discutir alguns problemas associados à gestão financeira de cooperativas, em função de suas características organizacionais particulares. Cooperativas constituem-se em um nítido exemplo de como a forma organizacional da firma pode afetar suas decisões financeiras, conforme sugerido por FAMA \& JENSEN (1985).

Desafios têm sido impostos pela busca de alternativas à obtenção de recursos próprios e pela redução dos entraves à captação de capital de terceiros (dívidas), bem como pela necessidade de definição de critérios rigorosos de rejeição ou seleção de projetos, com ênfase na avaliação do custo do capital próprio, a fim de evitar os incentivos à seleção de investimentos de valor presente líqüido negativo.

A questão-chave é aumentar o grau de incentivos organizacionais, por meio de definição e troca mais eficiente dos direitos de propriedade sobre "resíduos", muito embora existam limitações impostas pelos princípios doutrinários do cooperativismo. Mormente, torna-se preciso avaliar os riscos gerados por ativos específicos investidos pela cooperativa associados à possibilidade de ações oportunistas por parte dos cooperados, a fim de embasar a seleção de projetos, o grau de diversificação e até mesmo as decisões de estrutura de capital.

$\mathrm{O}$ texto é eminentemente conceitual e se propõe a abrir espaço para futuras pesquisas, especialmente de ordem empírica. Sugere-se a observação do comportamento das cooperativas com respeito à sua estrutura de capital, em função de diversas variáveis explicativas, tais como o seu tamanho, os padrões de governança internos, o nível de especificidade dos ativos, dentre outros. Decisões de investimento também merecem ser analisadas tendo em vista os efeitos do custo do capital próprio associado à ação de grupos de influência e de um monitoramento ineficaz dos agentes da cooperativa.

Sem dúvida, as experiências recentes de abertura de capital, remodelagem dos padrões internos de governança, e constituição de alianças estratégicas entre cooperativas e outras organizações, tanto no Brasil quanto no exterior, constituem-se em oportunidade ímpar para 
investigações de cunho empírico. Tais estudos podem ser realizados por meio de casos, a fim de obter detalhes e insights acerca do tema, e por pesquisas de cunho mais quantitativo, com amostras maiores e maior poder de generalização dos resultados.

\section{Referências Bibliográficas}

BIALOSKORSKI NETO, S.: "Agribusiness cooperativo: a questão do capital nas empresas de trabalho.” Revista Preços Agrícolas, 118: 11-13, 1996.

BIALOSKORSKI NETO, S.: "Gestão do agribusiness cooperativo.” In: BATALHA, M.O. (coord.) Gestão Agroindustrial. Vol.1, Editora Atlas, São Paulo, 1997.

BIALOSKORSKI NETO, S.: Cooperativas: Economia, crescimento e estrutura de capital. Tese de Doutorado, ESALQ/USP, 1998.

BIALOSKORSKI NETO, S.; NEVES, E.M. \& MARQUES, P.V.: "Agribusiness cooperativo, eficiência e princípios doutrinários." Revista de Economia e Sociologia Rural. 33: 85-121, 1995.

COLLINS, R.A.: "The conversion of cooperatives to publicly held corporations: a financial analysis of limited evidence." Western Journal of Agricultural Economics, 16 (2): 326-30, 1991.

COOK, M.L.: "The Role of Management Behavior in Agricultural Cooperatives." Journal of Agricultural Cooperatives, Vol. 9, 1994a.

COOK, M.L.: "The evolution of U.S. agricultural cooperative financial strategies." Paper apresentado no IV Seminário Internacional PENSA de Agribusiness, Águas de São Pedro, 1994b.

COOK, M.L.: "The future of U.S. agricultural cooperatives: a neo-institutional approach." American Journal of Agricultural Economics, 77: 1153-59, 1995.

COOK, M.L. \& ILIOPOULOS, C.: "Solutions to property rights constraints in producer-owned and controlled organizations: prerequisite for agrichain leadership?" In: Proceedings of the Third International Conference on Chain Management in Agribusiness and the Food Industry, Wageningen Agricultural University, May 1998.

FAMA, E. \& JENSEN, M.: "Separation of Ownership and Control." Journal of Law and Economics, 26: 301-25, 1983.

FAMA, E. \& JENSEN, M.: "Organizational forms and investment decisions." Journal of Financial Economics, 14: 101-19, 1985.
FULTON, M.E.; FULTON, J.R.; CLARK, J.S. \& PARLIAMENT, C.: "Cooperative growth: is it constrained?" Agribusiness, 11 (3): 245-61, 1995.

HANSMANN, H.: The ownership of enterprise. Cambridge: Harvard University Press, 1996.

HARRIS, A.; STEFANSON, B. \& FULTON, M.E.: "New generation cooperatives and cooperative theory." Journal of Cooperatives, 11: 15-28, 1996.

HARRIS, M. \& RAVIV, A.: "The theory of capital structure." Journal of Finance, 46(1): 297-335, 1991.

JACOBSON, R.E. \& O'LEARY, C.: Dairy cooperative issues in Ireland with special reference to PLC activities. Cork, Ireland: Center for Cooperative Studies, 1990.

JENSEN, M.C. \& MECKLING, W.C.: "Theory of the firm: managerial behavior, agency costs, and ownership structure." Journal of Financial Economics, 3: 305-360, 1976.

KATZ, J.P.: "Managerial behavior and strategy choices in agribusiness cooperatives." Agribusiness, 13(5): 483-95, 1997.

MILGROM, P. \& ROBERTS, J.: Economics, Organization and Management. New Jersey: Prenctice Hall, 1992.

MODIGLIANI, F. \& MILLER, M.: "The cost of capital, corporation finance and the theory of investment." American Economic Review, 48: 261-97, 1958.

MYERS, S.: "The capital structure puzzle." Journal of Finance, 39: 575-92, 1984.

REQUEJO, L.M.H.: "Lack of monitoring agricultural cooperatives in Brazil: evidence and prospects of improvement." Anais do I Congresso da SBI-Agro, Belo Horizonte, 1997.

SCHARADER, L.F.: "Equity capital restructuring of cooperatives as investor-oriented firms." Journal of Agricultural Cooperation 4: 41-53, 1989.

SEXTON, R.J. \& ISKOW, J.: "What do we know about the economic efficiency of cooperatives: and evaluative survey." Journal of Agricultural Cooperation, 8: 15-27, 1993. 
TRECHTER, D.D.: "Impacts of diversification on agricultural cooperatives in Wisconsin." Agribusiness, 12 (4): 385-94, 1996.

VITALIANO, P.: “Cooperative enterprise: an alternative conceptual basis for analyzing a complex institution." American Journal of Agricultural Economics, December 1983: 1078-83.

WEDIG, G.J.; HASSAN, M.; MORRISEY, M.A.: "Tax-exempt debt and the capital structure in nonprofit organizations: an application to hospitals.” Journal of Finance, 51(4): 1247-83, 1996.

WILLIAMSON, O.E.: The Economic Institutions of Capitalism. New York: The Free Press, 1985.
WILLIAMSON, O.E.: "Corporate governance and corporate finance." Journal of Finance, 43(3): 567-91, 1988.

ZYLBERSZTAJN, D.: "Organizational challenges for farmers cooperatives." In: Symposium of the International Agribusiness Management Association, San Francisco, CA, 1993.

ZYLBERSZTAJN, D.: “Organização de cooperativas: desafios e tendências." Revista de Administração, 29(3): 23-32, 1994.

ZYLBERSZTAJN, D.: "Entre o mercado e a hierarquia: análise de casos de quebra contratual no agribusiness." Série Estudos Temáticos n.1, PENSA-FEA/USP, 1996.

\title{
FINANCIAL DECISIONS IN COOPERATIVES: ORIGINS OF INEFFICIENCY AND POSSIBLE SOLUTIONS
}

\begin{abstract}
This paper discusses the impact of certain organizational characteristics on financial decisions of cooperatives. A theoretical analysis is presented, including the discussion of some important variables to study capital structure and investment decisions in cooperatives, such as the nature of equity, cost of capital, organizational incentives, and specificity of assets. The main challenge is the design and implementing an organizational structure to attract equity capital, thereby reducing constraints to debt financing. Furthermore, the design of a proper incentive structure is needed to avoid the selection of projects with negative net present value - a typical problem in cooperatives due to the underestimation of the marginal cost of equity capital. This is a conceptual study suggesting some relevant topics for further theoretical and empirical research.
\end{abstract}

Key words: cooperatives, property rights, finance, capital structure, investment decision. 